Article

\title{
Hot Spots and Not Spots: Addressing Infrastructure and Service Provision through Combined Approaches in Rural Scotland
}

\section{Sarah Skerratt}

Rural Society Research, Scottish Agricultural College, King's Buildings, West Mains Road, Edinburgh, EH9 3JG, UK; E-Mail: sarah.skerratt@sac.ac.uk; Tel.: +44-131-535-4335;

Fax: +44-131-535-4345.

Received: 11 May 2010; in revised form: 5 June 2010 / Accepted: 7 June 2010 /

Published: 17 June 2010

\begin{abstract}
There is widespread acceptance that the absence or presence of infrastructure and services in rural areas can lead to cycles of decline or resilience in these localities. It is also accepted that in remoter areas, population sparsity leads to a higher unit cost for delivery of services and infrastructure, and that private sector providers do not find such areas attractive for investment. At the same time, there is a reduction in spending capability within the public sector due to the significant impact of economic crisis on their resource base, affecting provision of services. How are these seemingly intractable challenges being addressed? Using an interpretive policy analysis approach [1] and narrative tools, the storyline of policy statements, approaches and policies in Scotland is presented and discussed, within a wider European setting. This is complemented by a brief presentation of public-private and third sector initiatives in response to service and infrastructure challenges in rural Scotland. The paper concludes with the argument that we are facing two alternatives - the current "hot spots" and "not spots" pattern of provision, where the fittest survive, or further shifts towards strategic, cross-sectoral investment which gives scope for more cohesive development for rural communities.
\end{abstract}

Keywords: rural services; Scotland; community resilience; interpretive policy analysis; narrative analysis 


\section{Introduction}

As outlined in the following section, there is widespread acceptance - in academic research and in policy statements and interventions - that the absence or presence of infrastructure and services in rural areas can lead to cycles of decline or resilience in these localities. It is also accepted that in remoter areas, population sparsity leads to a higher unit cost for delivery of services and infrastructure. For this reason, providers from the private sector do not find such areas attractive for investment, due to low potential and actual returns on their investment. Coupled with this investment situation is a reduction in spending capability within the public sector due to the significant impact of economic crisis on their resource base. This affects both direct public sector provision of services and delivery through those organizations with which the public sector has arrangements or contracts. How are these seemingly intractable challenges - and their recognized implications for rural sustainability—being addressed?

Sustainability, for the purposes of this paper, refers to the maintenance of community options for adaptation. That is, given the link between infrastructure and services and community survivability - particularly in remoter areas - it is important to examine the extent to which the presence of such infrastructure and services continue to give local, place-based communities the context within which to make choices about their future. These choices may relate to: business inward investment; starting-up (or continuation) of micro-enterprises; retention of young people in their communities, through — for example — accessible primary and/or higher education (for example online) in remoter areas, and the presence of affordable housing; the availability and accessibility of public transport in order to access jobs, health and other services; the presence of broadband infrastructure by which to access information about jobs, council services, allow home-working, support remote ICT-enabled diagnostics in primary health care, as well as entertainment and wider opportunities; and location choices due to accessibility of primary health care. This nexus of infrastructural and service components collectively serve to provide the context within which individuals and communities can choose how, when and where to develop, and thus provide a key component of their adaptive capacity.

This paper, therefore, does not argue that infrastructure and service development are prioritized by every community, since some choose to move to, or remain in, rural areas because they are not part of, for example, the "always-on" society. What is argued here however, is that, from a social justice perspective, communities will be more sustainable (using the definition outlined above) if they have the opportunity to choose whether or not to avail themselves of the services and infrastructure that are available in their area, and whether that choice is permitted due to its presence, cost and accessibility.

This challenge of service and infrastructure provision and rural sustainability (as defined above) is examined in this paper through the lens of interpretive policy analysis [1] within the public sector. The analysis focuses particularly on the early-mid stages of such analysis - that of identifying the documents and statements which clearly indicate the "framing" of the problems, together with the range of actions that seek to address these problems. A narrative approach to policy document analysis is used, and seeks to highlight the dominant narrative, plus indicate associated actions by those 'on the ground'. Specifically therefore, my policy analysis examines infrastructure and services in rural Europe, and then in rural Scotland. For Scotland, I first construct a policy timeline and "storyline" (see below for definitions) from early 2000 (following devolution in 1999), through to post-2007 when a 
major reform of local government policy and spending took place. Secondly, I look briefly at the activities of the public-private sector. Thirdly, I examine the ways in which people on the ground have taken service provision into their own hands in order to address shortfalls and market failure.

I conclude the interpretive policy analysis with questions concerning the "hot spots" and "not spots" of infrastructure and service provision which persist in rural Scotland. I focus particularly on whether what can be termed a "Darwinian" approach (where the fittest survive) to such provision is acceptable, or whether there should be strengthening of a more strategic, cross-sectoral investment approach to these challenges. I argue that these are critical normative questions, with investment and partnership being essential to enhancing community resilience and adaptive capacity in Scotland's remotest rural areas. Finally, I indicate the remaining areas for argumentation and deliberative analyses of public policy in the domain of rural infrastructure and services.

\section{Why Rural Infrastructure and Services Matter to Rural Sustainability: Perspectives from Policy and Academic Literature}

As has been stated, within both policy and academic literature it is accepted that the presence or absence of infrastructure and services in rural areas can lead either to wellbeing and prosperity, or conversely to cycles of decline. The main arguments are now briefly discussed.

\subsection{Perspectives from European and OECD Policy}

Firstly, there is the reasoning (underpinning much EU rhetoric and Member State policy) that the presence of services and infrastructure directly supports - and perhaps engenders and maintains - the cohesion of areas and regions, and the inclusion of citizens, by providing access to services and opportunities and business development. A key, formative statement is from the European Commission in 2004 [2]:

"The access of all citizens and enterprises to affordable high-quality services of general interest throughout the territory of the Member States is essential for the promotion of social and territorial cohesion in the European Union, including the reduction of handicaps caused by the lack of accessibility of the outermost regions..." (Section 3.3, p. 8).

Further, analysis by the Organization for Economic Cooperation and Development (OECD) shows that the presence of infrastructure is an engine of positive demographic change and economic growth [3]. When this symbiotic relationship becomes dysfunctional through lack of investment or spends, social exclusion (based on partial access to potentially poor quality provision) is likely, and it is argued that this matters when considering equity and parity amongst citizens, irrespective of where they may live. Further, it is felt that such effects are disproportionate in their significance in more remote areas, due to distance from markets, service, networks of support, and ways to engage in economy and society. These disadvantages are not presented by the authors as scenarios only. Rather, they are argued as already being evidenced in rural areas. OECD's [3] analysis links lack of critical mass in rural areas for services and infrastructure to a "circle of decline": 
Figure 1. Circle of declining rural regions (OECD, 2006b, p. 32).

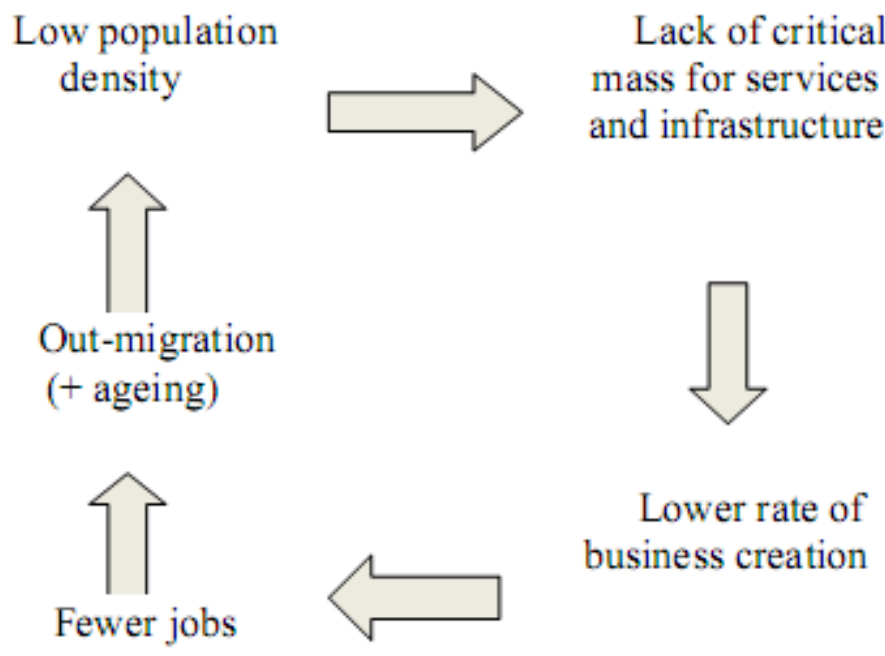

\subsection{Perspectives from the Research Literature}

Such analysis by policy bodies echoes academic research in this area, for example, the framework of Zones of Accumulation and Depletion [4]. This framework shows "accessible rural" areas demonstrating growth, commuting, higher activity rates and lower unemployment. Conversely, "remote rural" areas show demographic ageing, low human capital, and poor infrastructure. It is important to note, however, that there are arguments that state these linkages can be somewhat over-simplified. For example, the accumulation/depletion framework contains within it assumptions that "accessible rural" areas are more energized and better resourced. One has to be careful and instead ask "accessible to what?", since some rural towns are areas of high unemployment and poor services and amenities. So, areas of higher population density in rural areas do not necessarily equate with inward investment and vitality. Similarly, the simplification that remote rural equates with low human capital has been questioned.

Wider research shows rural areas as being characterized in terms of the dispersed nature of their population, with associated 'frictions of distance' [5], comprising specific challenges to accessing a range of services. In addition to the dispersed nature of rural populations, the agencies and individuals that seek to support rural development priorities, and provide information, are often themselves geographically spread [6]. This can, and does, lead to a sense of isolation from one another, and from the information and debate on rural regeneration problems and solutions. Such individuals experience frustration, knowing that 'all that information is out there somewhere' and that 'someone else must have faced what I am facing' - but who they are, where they are, and what they have learnt and found out, remain inaccessible.

This "distance" is well-evidenced in rural Scotland, particularly when we examine broadband infrastructure and services. Research shows a new digital divide opening up between urban and rural Scotland [7,8], where the default is not the 24/7, metropolitan, always-on milieu. This contrasts with the utopian visions of the "death of distance" [9] which information and communications technology were supposed to herald [10]. Optimistic commentators laud the apparent ubiquity of access to always-on, high-speed, computer-mediated communication (CMC) through broadband-enabled email, 
websites and portals. This, in turn, skews channels of information and service provision towards online media.

Coupled with this, increasingly information, funding applications, access to government departments, is online, and this presumes affordable, quality access. Information provision, and networking (allowing for exchange of information and experience), are seen as critical for survival, socially, economically and environmentally [11]. Access to information, support, individuals with expertise, and up-to-the-minute news digests, are seen as important elements of 'social justice', and as such, should be available to all, irrespective of geographical location [12].

However, in rural Scotland, the experience is extremely patchy. This is also reflected in access to $3 \mathrm{G}$ mobile phone networks, through which internet access can be obtained. The "footprint" of such coverage remains primarily in the urban $10 \%$ of Scotland's land area, echoing the investment in next generation broadband where fiber optic cabling allows for higher-level use of applications [13]. Areas of higher population density clearly reduce costs in infrastructure per head, whereas in rural Scotland, building and/or improving such infrastructure from the copper wire and telephone exchanges is far more costly per unit. Thus, the knowledge economy, and connectivity in remoter rural areas, is still being hampered in rural areas by the infrastructure as it stands [8], with the pathway being that accessibility can reinforce accessibility (the corollary being that inaccessibility reinforces inaccessibility) [14]:

"Unevenness of development, a key feature in globalization, is in part a consequence of unevenness of accessibility at the large scale. This relationship is self-reinforcing and cumulative: 'stronger' places attract greater global accessibility, whether by transport links such as shipping and aviation, or by electronic communication: for example, the Internet is also viewed as reinforcing unevenness - an ironic consequence of a great technical achievement that had the apparent potential to iron out disadvantages of relative location" (p. 325).

\subsection{Access or Accessibility?}

The concept of "accessibility" rather than simply "access" is a critical component of the assessment of infrastructure and services provision in relation to the sustainability of rural communities [14-16]. Further, Farrington argues that accessibility needs are as "complex as the lives of individuals, communities and businesses who experience these needs" (op. cit.), and is inherently personal rather as well as being an attribute of place:

"Accessibility is at least as much about people as places. A place is not just 'more' or 'less' accessible, but accessible relative to people in all their different circumstances: people experience more, or less, access to places. This emphasis gives accessibility concepts a significant role in appraising the policies which affect people's accessibility, since it gives a framework for understanding and analyzing the way in which accessibility levels vary with personal characteristics such as age, wealth and health. This does not mean, though, that people live and operate spatially; place is also an important theme in their experience, and their location at any given time is an important factor in their experienced accessibility" (p. 320) [14]. 


\subsection{Dominant Explanatory Variables for the State of Rural Services and Infrastructure}

The typical explanatory variables for this situation can be summarized as follows (see [10]).

Firstly, low population density (compared with urban settings) and sparsity, that is, a small number of people and communities spread across substantial distances. Secondly, in market terms, this low population density is described as low or insufficient "critical mass", that is, a small potential and actual customer base. This in turn reduces return on private (and public) investment and thus desire by private investors to compete for provision. Thirdly, a low population base leads directly to higher unit cost per head, which is typically experienced not only by the provider but also passed directly to the consumer. Finally, this population density pattern is underpinned by demographic structures - that is, an aged and ageing rural population. This, in turn, has two broad implications; firstly, the elderly generally have a higher requirement for services, particularly in health and social care; secondly, a population balance that is more weighted towards the elderly is generally accepted as being less economically productive, thus causing further dissuasion of investment in such areas [17], thus feeding the "circle of decline".

Analyses and statements at European, and OECD, levels appear therefore, to reflect the findings from the academic research, that there is a quasi-causal [18] link between the state of infrastructure and services, and the developmental potential - through access-for communities and individuals. This context is the wider setting for the interpretive policy narrative presented below, on how Scotland's policies and practices are seeking to address the persistent challenge of infrastructural deficits and their implications. The following section gives a descriptive account of the current evidence of the state of infrastructure and services in rural Scotland, before going on to describe the methods used here for the analysis of policies and actions for addressing what are seen as persistent challenges.

\subsection{The State of Infrastructure and Services in Rural Scotland}

It is argued that the underpinning pattern described in the wider policy statements and academic research (above) is reflected clearly in rural Scotland [13]. Components of this are now briefly explored.

Firstly, in examining the provision of high-speed broadband [19], we see that, through European investment and regulation, broadband is being rolled out to remoter areas, where in the UK for example, figures show that $99.6 \%$ of the population has access to standard broadband. However, the experience of such infrastructure, below the headline figures, is extremely variable for individuals and communities in rural Scotland [8]. This variability is primarily in terms of quality, speed, contention constraints (the more people are using it in a locality, the slower it becomes) and the generally higher cost per month due to lack of competing providers [20,21].

Secondly, when considering rural residents' access to various health services, data (Rural Scotland Key Facts) show that provision of, and access to, General Practitioners (GPs), hospitals, dentists and chemists, is more difficult for rural than urban residents. This is particularly the case for accessing specialist care, and patient access to emergency care [22].

Thirdly, evidence shows that access to mains electricity and gas networks (for domestic heating) is a key factor in the incidence of fuel poverty [13]. A household is defined as being in fuel poverty if it spends more than $10 \%$ of its income on household fuel use, and in "Extreme Fuel Poverty" if a household has to spend more than $20 \%$ of its income on fuel. Thirty-seven percent of those in rural 
areas suffer fuel poverty compared to just over a fifth in urban households; $16 \%$ of rural households are in extreme fuel poverty, making it almost three times as prevalent in rural households as urban (op. cit.). Research has shown that the most effective way to remove a household from fuel poverty is to fir a gas central heating system. However, many fuel-poor properties are in rural and remote areas where the cost of providing a gas supply would be uneconomic for the provider and thus for the user.

Fourthly, affordable housing remains a major challenge for the sustainability of rural communities in Scotland. The implications of this lack of basic infrastructure are that younger generations are priced out of their locale, particularly in areas closer to commuting towns and cities; and that businesses find it hard to establish or grow due to lack of affordable housing stock for their workforce. In many areas of rural Scotland, average house prices [23] sit at least 11 times average earnings for 2008. Further, in pockets of rural Scotland in the Borders, Argyll, and parts of the North East and Inverness-shire, the average lower quartile to house prices ratio still shows such properties as being unaffordable, being, again, at least 11 times average earnings in those areas (p. 31) [13].

Finally, rural public transport is closely related to the problems of ensuring access to other services [24]. Many rural areas still lack adequate access, with Scottish Government figures [25] showing a higher percentage of householders in remote areas with no bus service. Data relating to car ownership show that on average, $21 \%$ of rural households are without access to a car. This is then coupled with higher petrol costs in rural areas, with evidence of a higher proportion of the household budget being spent on fuel for cars than in urban areas. Further, data show that without exception, average travel times to a range of services are longer in rural than urban areas.

These examples, and how they combine, show the interconnected, self-feeding effects of reduced or poor quality infrastructure provision, and its implications for service access and accessibility. This would imply that composite "accessibility" rather than simply "access" must therefore be considered. Over three quarters of the $15 \%$ most access-deprived datazones in Scotland are found in accessible and remote rural areas (p. 32) [13].

\section{Investigating the Narrative in Scotland: Methodological Approach}

\subsection{Interpretive Policy Analysis}

The significance of infrastructure and services to rural sustainability is examined through a focus on the public sector statements and interventions, as well as 'on-the-ground' actions, in Scotland, from 1999-2009. Through the lens of interpretive policy analysis [1], this specific investigation of infrastructure and services in rural Scotland is set within the wider research literature and European and OECD statements (cited above).

Within interpretive policy analysis, there are a number of recognized steps [26], ranging from exploration of position documents, through interviews and observation with those co-constructing such documents and policies and overseeing their implementation, to those holding various positions on the "problems" and "solutions" being identified.

In this paper, I focus on the early-to-mid stages of such analysis, identifying the documents and statements which clearly indicate the "framing" of the problems, thus establishing the "storyline" through a narrative and timeline approach. A "storyline" is based on a "timeline", the latter being a mere chronicle of events, the former giving an interpretation of those events. The storyline approach is 
underpinned by exploration of publicly-available documents, using a recognized narrative approach which cites textual extracts from the source documents as evidence of priorities, language, framing and problem/solution definition. Analysis of the public policy storyline is then coupled with a brief desk-based review of actions taking place by actors from the private sector and those in rural communities 'on the ground'.

This preliminary triangulation of findings therefore presents for the reader the multiple ways in which the challenge of an infrastructural and service deficit in rural Scotland is being described and the attempts being made to address it. Towards the end of the paper, I indicate the remaining areas for meta-narrative and deliberative analyses of public policy, thus reflecting the analysis back to the persistent themes in the literature and policy reviews outlined above.

\subsection{Defining Infrastructure and Services in the Context of This Paper}

When examining the ways in which "infrastructure" is described in a European context, one sees that it can have a range of definitions, depending on the starting-point; a few examples illustrate this diversity. The Trans-European Transport Networks focuses on land and sea transport, the Cross-Border e-Government services works on trans-European telecommunications and high-speed broadband infrastructure. The EU's Infrastructure Magazine focuses on five infrastructure sectors: Construction, Renewable Energy, Transportation, Security and Communications, and Waste Management. EU Enterprise and Industry's take on infrastructure comprises high-speed broadband, electricity grids and associated smart electricity systems. Following the terrorist attacks of 9/11, the European Commission established (in November 2004) the seemingly all-encompassing list of "European Critical Infrastructure" (ECI), comprising: Energy; Nuclear industry; Information and Communication Technologies; Water; Food; Health; Financial; Transport; Chemical Industry; Space; Research Facilities. In 2006 and 2007 the OECD reviewed the sustainability and investment needs of "global infrastructure" to 2030, and focused on Telecoms, Land Transport, Water and Electricity [27], and Electricity, Water and Transport [28].

In reviewing these publications, [29] gives a useful over-arching definition that distinguishes between "infrastructures" on the one hand, and "services" on the other:

"Infrastructure is a vital means for ensuring the delivery of goods and services that promote prosperity and growth and contribute to quality of life" (p. 1).

On this basis, they argue that infrastructure therefore:

"underpins social well-being, the health and safety of citizens, and the quality of their environments. Infrastructure is more than just a means to an end-it embodies an economic sector in its own right, commanding huge investment in capital equipment and employment, as well as procurement services, financing and so on" (p. 1).

It is this distinction that is used for the purposes of this paper. Thus, "infrastructure" comprises, largely, roads, telecommunications including broadband, air and water travel, electricity and fuel. "Services" comprise those provisions which are subsequently delivered through such infrastructure - health, education, social services etc. The area of (affordable) housing provision still remains ambiguous in terms of definition, with some examples citing it as a service, some as 
infrastructure. Given the centrality of affordable housing to rural sustainability (discussed later in the paper) it is important that this particular component does not fall between the two definitions.

\section{How Are These Seemingly Intractable Challenges Being Addressed in Rural Scotland? Evidence from Interpretive Policy Analysis}

Access to rural infrastructure and services, and accessibility to a lesser extent, are being addressed in a number of ways in rural Scotland. In my policy analysis, I look firstly at national and local government initiatives, then specially-rural programs and schemes which approach "rural" as a space and place that is considered particularly challenging for access provision. I then briefly examine public-private sector initiatives and conclude this section by briefly looking at informal voluntary and third sector interventions - that is, actions by agents on the ground who are seeking to implement their own change.

\subsection{Policy and Public Sector Arena in Scotland}

The challenge of infrastructure and service provision in rural Scotland, which covers approximately $90 \%$ of its land mass and approximately $20 \%$ of its population-around one million people - is not only being discussed in 2010. Specifically, one can see policy statements, working group reports, and prioritized, strategic action plans dating back to the 1990s (with the 1997 Rural Framework [30]), and particularly since 2000, following the establishment of the Scottish Parliament in 1999. The following timeline (Figure 2) brings together the key outputs and statements which form the content of the storyline.

Figure 2. Timeline underpinning the Storyline of outputs, statements and strategies addressing infrastructure and services challenges in rural Scotland.

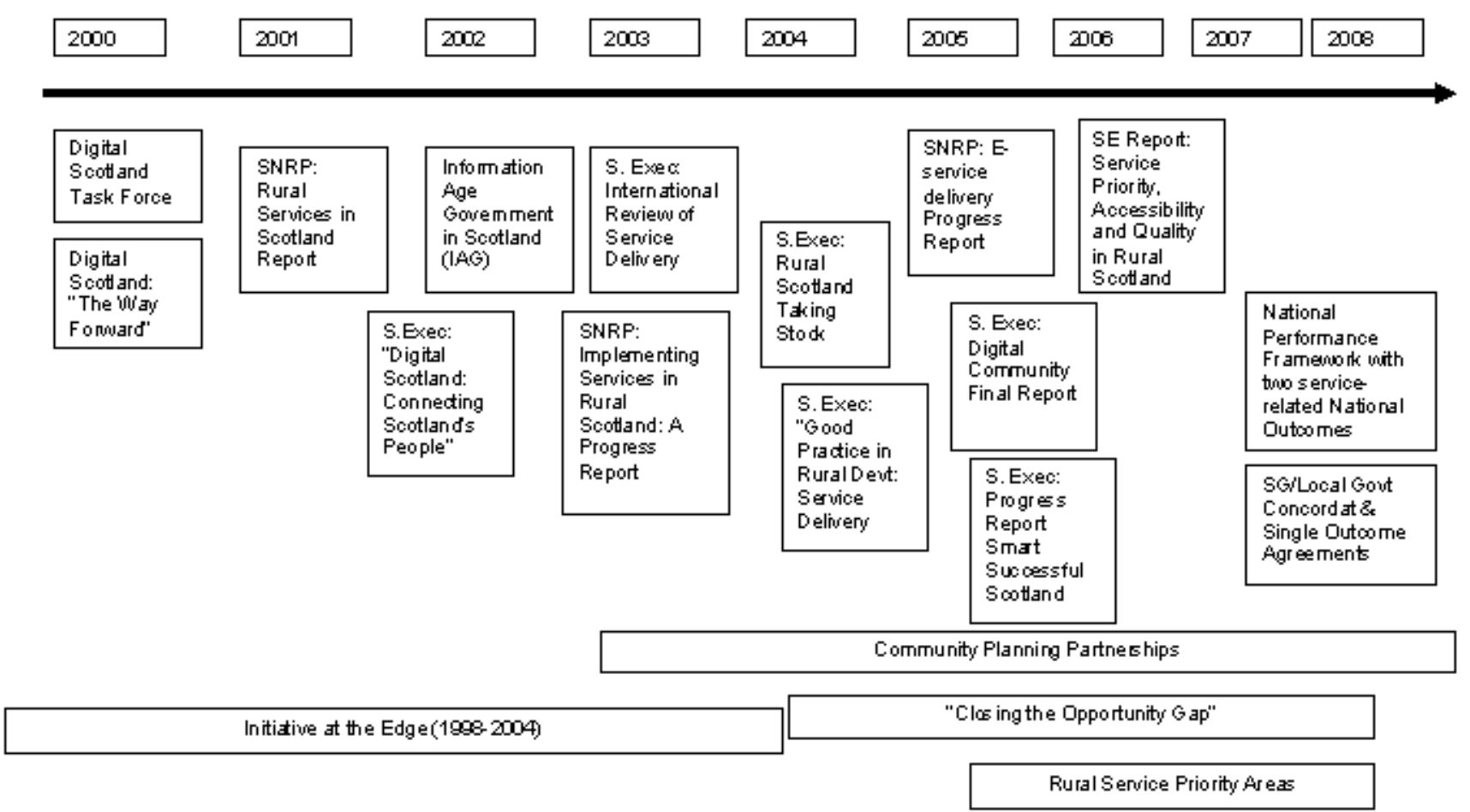


An analysis of this storyline shows that the reviews, statements and practice of service delivery in rural Scotland can be categorized as thematic (such as "digital Scotland"), spatial and locational (such as "Initiative at the Edge" and "Rural Service Priority Areas"), and cross-theme (such as Community Planning Partnerships, and most significantly, the National Performance Framework).

For the purposes of this paper, I will briefly explore two spatial and locational programs, and then the cross-theme initiatives, programs and strategies which are currently in place. Given that a narrative approach underpins this policy analysis, the reader is presented with a number of quotes from the relevant documents (including evaluations), as these give insights into the importance of particular priorities, concerns, terms, and the identification of specific 'problems' and 'challenges' viewed as critical at the time. These citations are important components of the 'framing' of the infrastructure and services challenge, as presented by the public sector.

Initiative at the Edge (Iomairt aig an Oir) (1998-2004): This program was instigated by the then Scottish Office in 1997, and launched in March 1998. The purpose was "to concentrate attention and effort on tackling the problems faced by the most fragile areas of northern Scotland". A total of 46 "fragile" communities were identified, with eight particularly vulnerable communities selected as pilot areas [31]. The 2007 Review and Evaluation of Initiative at the Edge [32] states that:

"It empowers communities in some of Scotland's most remote and fragile areas to identify their needs for area regeneration, consider what actions might be appropriate, and develop relevant projects in partnership with public sector agencies. One of the distinctive features of IatE is that there is no central source of funding and its success depends overwhelmingly on the refocusing of the support given by public sector agencies working in partnership with community groups within the IatE areas" (p. ii).

The evaluation found substantial variation in the degree of partnership between the Initiative (IatE) and other agencies in the area, and in the extent of "mainstreaming" of Initiative-type priorities within such departments:

"Noticeably higher levels of agency engagement seemed to have occurred between IatE groups and local authority central/corporate services, Highlands and Islands Enterprise (HIE) and the local enterprise network, Communities Scotland and the Crofters Commission. By comparison, engagement with health boards, certain other local authority departments (such as education), public transport agencies and ferry services was noticeably weak or absent. Amongst the partner agencies, there was little evidence of systematic sharing of good practice between agencies that has been learned from IatE areas. If IatE had really penetrated the mindset of mainstream delivery this would be expected to be a prominent feature of activity on the ground" (pp. iii-iv).

IatE operated over a clear five-year timescale that had been designed "to act as a catalyst to focused and energetic commitment by all parties to achieving the aims and objectives of the Initiative" (p. iii). The evaluation found that the IatE designation was removed "prematurely", since:

"There was more success in funding specific capital projects than in securing changes to service provision that required an ongoing funding commitment" (p. iii). 
This issue of short-term spending, rather than investment, is returned to later in the paper as a key component of sustainability in and of rural communities.

Rural Service Priority Areas (2005/6-2008): The 22 Rural Service Priority Areas (RSPAs) have their origin in the Scottish Executive's 'Closing the Opportunity Gap' social justice Strategy. The Strategy included "a commitment to improving access to high quality services for the most disadvantaged groups and individuals in rural communities as a means of enhancing quality of life and access to opportunity". One of its six Objectives was:

To improve access to high quality services for the most disadvantaged groups and individuals in rural communities - in order to improve their quality of life and enhance their access to opportunity.

This Objective led to a specific Target H: "By 2008, improve service delivery in rural areas so that agreed improvements in accessibility and quality are achieved for key services in remote and disadvantaged communities". The Scottish Government website [33] explains why this Target was felt to be important:

"A defining feature of some rural areas is a lack of accessibility for key services. This can have a significant impact on the quality of life of communities and individuals. Research highlights that disadvantage in rural areas is often caused or exacerbated by distance or the uneconomic nature of providing services (due to lower population numbers) and by stigma that can be associated with accessing some services in a small community. Rural services are provided by a number of delivery agents, including the Voluntary Sector, and so the target focuses on coordinating and improving service delivery through innovative approaches, such as co-location, integrated provision, mobile and outreach services. The intended improvements to accessibility and quality should deliver a higher quality of life and enhance opportunities for the most disadvantaged groups and individuals living in rural communities".

With Target $\mathrm{H}$ in mind, the Scottish Executive then designated 22 Rural Service Priority Areas (RSPAs). These areas had been identified as experiencing particular disadvantage in service provision, access to services and subsequent opportunities.

In January 2005, the Scottish Executive announced the selection of the 20 RSPAs, with a total of 22 areas designated by July 2005. In April 2005, research began with area Community Planning Partnerships [34] to identify services which were considered 'key' to sustain "thriving rural communities" [35]. In December 2005, Scottish Executive announced funding support for delivery of targets in RSPAs worth a total of $£ 2.2 \mathrm{M}$ in financial year $2006 / 2007$, divided equally across the RSPAs, giving approximately $£ 100,000$ per area for improvements to targeted rural services. By May 2006, the Government announced that 91 service improvement targets had been agreed with the 8 Community Planning Partnerships with responsibility for the 22 RSPAs.

The measuring of reaching Target $\mathrm{H}$ is described as being through the RSPAs: 
"The target is complex in that access and quality targets will be set for key services in each Rural Service Priority Area (RSPA). Since each target will be set as improvements from baseline, success will have been achieved if agreed improvements have been made by $31 \mathrm{st}$ March 2008".

The RSPAs were then superseded (and thus discontinued) by the establishment in 2007/2008 of the National Performance Framework. As a consequence, no further monitoring of Target $\mathrm{H}$, and the extent to which it was reached through the RSPAs, has taken place.

The National Performance Framework, the Concordat, and Single Outcome Agreements: The National Performance Framework 2007 was introduced in Scotland by the new Administration as the key component of the Economic Strategy. Scottish Government now has a single Purpose, and all activities must deliver to this Purpose:

"To focus Government and public services on creating a more successful country, with opportunities for all of Scotland to flourish, through increasing sustainable economic growth".

There are five Strategic Objectives which seek to deliver to the Purpose: Wealthier and Fairer, Smarter, Safer and Stronger, and Greener. A key shift here is towards Outcomes-based activities, rather than outputs-based. And thus 15 National Outcomes now form the framework within which all Government activities (from national through to regional/local authority level) must be aligned. The two National Outcomes of relevance to this paper [36] are:

- We live in well-designed, sustainable places where we are able to access the amenities and services we need (Outcome 10)

- Our public service are high quality, continually improving, efficient and responsive to local people's needs (Outcome 15)

As part of this major reform, Scottish Government, in partnership with the 32 Local Authorities in Scotland, formed The Concordat. This encompassed within it Single Outcome Agreements, whereby Local Authorities commit to delivering to National Outcomes which sit within the National Performance Framework. Instead of central government in Edinburgh setting local government budgets for different components of their activities, Outcomes-based structures and processes were put in place from $1^{\text {st }}$ April 2008. This means that each Local Authority is responsible, within their overall agreed budget, for delivering to the nationally-agreed five Strategic Objectives and the 15 National Outcomes. Evaluation criteria, and indicators of progress are devised by local government, and the national-level Outcomes are variously interpreted so that they "fit" with circumstances and priorities of each region [37]. Thus, rural local authority areas [38] that are made up of islands (such as Orkney, Shetland and the Western Isles) are addressing their priority issues through the 15 National Outcomes in ways that differ from rural local authorities in the mainland, such as central and southern Scotland. Local Authorities deliver such services either directly, or through Service Level Agreements with providers (such as Third Sector, voluntary agencies, social enterprises).

Each of the 14 "rural" Local Authorities therefore has to consider how best to deliver to rural areas, and where the Community Planning Partnerships are working well, there is discussion involving a range of stakeholders as to how this is best approached. The national government has taken the stance 
of "rural mainstreaming" that is, the presumption that rural can be sufficiently integrated within activities such that any differential impacts in policy likely to be experienced in rural areas are identified and addressed. One Local Authority, the Scottish Borders [39], has put in place its own "rural proofing" [40] mechanism, which is the deliberate use of a checklist to ensure that differential impacts in its rural areas are at least identified. Similarly, Orkney Islands Council is investigating the possibility of "island proofing", since it faces the challenge of out-migration from its outer isles to its mainland, and wishes to ensure that policies do not enhance this trend.

\subsection{Public-Private Sector Activities in Infrastructure and Service Provision}

Rural broadband: In December 2005, rural Scotland saw the completion of the "Broadband for Scotland Rural and Remote Areas Supply Side Intervention" (SSI), at which point it was stated that every household had access to at least basic broadband [41]. In 2008, the Scottish Government signed an additional $£ 3.3 \mathrm{M}$ contract called "Broadband Reach" to make broadband more affordable, and in 2009 it was announced that telephone exchanges in rural areas would also be upgraded. All this forms part of Scottish Government's Universal Service Commitment to $0.5 \mathrm{Mbps}$ basic broadband. ISPreview [42] in 2009 argue, however, that "the numbers being reached by these initiatives is small..." and that "while Scotland's efforts should be celebrated, $0.5 \mathrm{Mbps}$ is not nearly fast enough to handle the content-rich nature of a modern internet environment, where high quality online video and download services are flourishing". In addition to government intervention, the European Economic Recovery Package should see approximately 2.9 M Euro for enhanced broadband infrastructure provision for Scotland's rural areas.

Access to health services: one of the key initiatives in addressing rural health care is the Rural General Hospital (RGH) concept, learning lessons from Australia. The six RGHs (Shetland, Orkney, Stornoway, Fort William, Oban and Elgin) are helping providers to face shared problems of maintaining consultant-led services in the face of increasing specialization and the European Working Time Directive. Alongside this, communications technology, through tele-care in remote delivery of services, is proving valuable, for example through tele-radiology and tele-histopathology, screening for emergency conditions, as well as paramedic pre-hospital thrombolysis supported by tele-links to coronary care. These developments are obviously increasingly dependent on reliable high-speed broadband infrastructure in order to function effectively and consistently.

Fuel poverty: the Scottish Government has set a target to end fuel poverty in Scotland by 2016 "as far as is reasonably practicable". The Government therefore instigated the Energy Assistance Package, managed by the Energy Saving Trust, which comprises advice and-where eligible - free insulation and grants for energy saving measures. Addressing fuel poverty specifically are five independent gas networks in rural towns (Stornoway, Wick, Thurso, Oban and Cambletown), supplied by natural gas by road tankers from a storage facility to satellite stations.

Affordable housing: the Scottish Government is investing through its Affordable Housing Investment Program, and the government-funded Rural Housing Service provides a range of services to communities and individuals to support access to affordable housing and grants (such as Rural Home Ownership Grants). Housing Associations, Registered Social Landlords and Small Communities Housing Trusts also play a role in addressing this ongoing rural challenge. 
Rural public transport: a number of short-term schemes and pilots have been run by Scottish Government, some in partnership with other agencies. These include the Rural Transport Fund, the Rural Community Transport Initiative and the Rural Petrol Stations Grant Scheme. In addition, private, and voluntary, schemes, some of which receive funds from the government or are self-funding, provide what is termed "Demand Responsive Transport" (DRT) where day to day service provision is shaped by the demands of users. Some of these are also run by the public sector, such as local authorities (for example in Aberdeenshire).

\subsection{Formal Voluntary, Informal Voluntary and Collective Action}

Clearly, national, regional and local initiatives, as outlined in the preceding section, deliver to many of Scotland's rural population. However, the importance of informal voluntary, and formal voluntary, action - as individuals and communities - is seen as vital to ongoing provision of services, particularly for the hard-to-reach [43].

Data point to the significance of volunteering and third sector activity to the ongoing vibrancy of communities across rural Scotland. Statistics show [44,45] that, per 1,000 of the population, rural Scotland has a higher number of charities than urban Scotland, with the inner and outer Hebrides and Northern Isles having the most charities and activity. People in rural Scotland give up their time to help and volunteer locally more than their urban neighbors (47\% and $29 \%$ respectively), and-in the context of provision of local hubs such as village halls-voluntary activity is critical to the survivability of many initiatives [46].

Typically, such activities are undertaken by individuals and groups where they perceive and experience "market failure" of provision, either for themselves or for others in their community. Funding is sought from charitable trusts, and from subsidized subscriptions, pay-for-use etc. Projects are typically pilot schemes, and, where successful (and where they are increasingly based on business and succession planning), they evolve into longer-standing programs.

Examples include the following: community transport mini-buses; community-owned village shops or post offices; childcare pre- and after school; support services and life-skills training for the "unintentionally homeless" (particularly young people who fall into this category); indoor health and leisure facilities to encourage healthier lifestyles; management of meeting places such as village halls; and organization of social care and addressing isolation, such as home visiting, lift sharing, lunch clubs, and shopping for food for housebound individuals.

In the current climate of a significant decline in public sector spend, there is increasing evidence of 'devolution' towards local level empowerment, and acquisition of assets and resources by communities for communities in rural Scotland (for the debates around this, see [21]). It is expected that the third sector-formalized and informalized - is likely to increase in activity, and associated expectations (both of the third sector and of government) will rise in relation to their role in service provision in rural Scotland. However, the challenge of funding for delivery through the third sector remains a considerable uncertainty. 


\section{And the Future-Implications for Sustainability?}

This paper has reviewed rural services and infrastructure, from a "bigger picture", pan-EU, pan-OECD perspective, a review of relevant academic literature, and through interpretive policy analysis of experiences in rural Scotland. This final section seeks to highlight key implications of the status quo, by providing further analysis of the policy and practice storyline (above), and concludes with questions concerning sustainability (as defined in the Introduction) and further research.

In summary, it is widely accepted that the presence or absence of infrastructure and services directly affects the vibrancy or decline of rural areas. The state of infrastructure and services reflects the high costs per head of provision, maintenance and improvement, and the fact that rural areas therefore remain less attractive for investment than population-dense areas such as cities and towns. The outcomes become composite and self-feeding for individuals and communities. State intervention in Scotland, over many years, has focused on access provision and to a much lesser extent on accessibility. A series of schemes and pilots has been implemented, and, with Government reform in 2007, an outcomes-based (longer-term) approach to services has been instigated, with the ambition of greater joining-up of initiatives. Alongside national and regional government programs, informal and formal volunteer activities are delivering in the interstices, where market failure does not provide for the hard-to-reach. There is little systematic evidence yet of the added value of these activities, although research in this area-beyond the anecdotal - is beginning, and will be invaluable.

As evidenced in the preceding policy analysis, although in Scotland we are witnessing a joining-up, in principle, through the National Performance Framework, the challenges of infrastructure and services are still being addressed through sectoral approaches-housing, education, roads, broadband, etc. However, the wider policy intelligence (such as EU and OECD) states that place-based, "territorial", cohesion approaches are required for such challenges to be coherently addressed. Interpreting this language for a Scottish context, therefore, it can be argued that there is a need to align further the national strategy with a strategic, cross-sectoral investment in Scotland's rural infrastructure and services. I now consider each of these terms in turn.

Firstly, "strategic" because interventions with a short lifecycle (often reflecting political lifecycles) can rarely address the cause, but rather of necessity focus on symptoms or outplaying of structural deficits in rural areas. For example, in their evaluation of the Initiative at the Edge scheme, the authors make the following observations:

"...we are in no doubt that the future of the Initiative depends critically on a change in the level of commitment of the key agencies at all levels and their approach to the allocation of resources to the needs of what have been identified as the most fragile of the fragile areas in the Highlands and Islands. Without more in the way of strategic direction and focused attention by key agencies we conclude that sustainable area regeneration and community development of the IatE areas is unlikely to be secured" (p. ix; emphasis added) [32].

This sentiment is echoed by the OECD review of Scotland's rural policy, in which they concluded that key priorities should include: 
"Service delivery policy and related investment strategies to tackle the challenges linked with quality education, the healthcare needs of an ageing population and the improvements of rural transport infrastructure" (p. 110, emphasis added) [24].

The Scottish Government reform of 2007 has presented us with the exciting prospect of coherent, strategic, outcome-based delivery. Outcomes are longer-term, and focus on where the Government wants to reach, and why, rather than solely on the means of delivering to potentially conflicting targets and outputs. The ambition of a "golden thread" running from national through to local is inherent within the National Performance Framework and the Single Outcome Agreements which seek to operationalise it. However, the tension clearly exists between encouraging "localism" through 32 Local Authorities interpreting national outcomes such that they "fit" local priorities, capacity and circumstance, and maintaining strategic, national direction [47]. Further, the evaluation of achievement of Outcomes is becoming more complex, as the 32 Local Authorities develop their independent indicator frameworks (some Local Authorities having hundreds of indicators), alongside the 45 national indicators [48] within "Scotland Performs". Nonetheless, a national, strategic framework within which Government, and other agency actions, can take place is a significant step.

Secondly, "cross-sectoral" It is perhaps a well-worn adage that joined-up initiatives are the way forward for delivery of sustainable, durable rural services. What further evidence do we have, for rural Scotland, that the need for such an approach is still a priority? When we consider accessibility to infrastructure and services, rather than only access, Farrington and Farrington conclude their analysis with the following emphatic statement of the imperative for such an approach:

"Accessibility planning as a tool, and greater accessibility as a goal, are potentially powerful drivers of policy because they require that policy sectors interact: otherwise the goal of achieving greater accessibility as a means of greater social inclusion and social justice cannot be fully attained" (p. 10) [15].

Further, within the context of social justice and sustainability, Farrington again states that:

"A cross-sectoral integrative policy element can be seen as a (necessary) means of achieving greater accessibility and thus greater social justice and sustainability" (p. 324) [14].

These comments echo those of the OECD analysis of the imperatives for Scotland's rural policy:

"A modern, multi-sectoral policy for the development of Scottish rural areas should include a careful, spatially differentiated, investment strategy in the key public service areas of education, healthcare and public transportation" (p. 125) [24].

Further, they bring to mind the evaluation of the Initiative at the Edge (2007) which highlighted that where there was a lack of mainstreaming of project ideas across sectors and agencies, there was less buy-in to the ideas and innovations, and less sustainability of projects.

There is anecdotal, variable evidence of inter-agency working, setting of priorities and decisions over appropriate implementation, within Community Planning Partnerships. The more effective of these CPPs could point the way to workable mechanisms for co-production of priorities and programs. Systematic analyses are required, however, in order to identify processes and outcomes that are based on such cross-sectoral working. 
Cross-sectoral, in its broadest sense, is not restricted to public sector. Rather, the working together of the private, public, and voluntary (informal and formal) is, in some cases in rural Scotland, evidenced as providing a composite approach to addressing rural infrastructure and service provision. As stated by the Scottish Executive in relation to Rural Service Priority Areas:

"Improvements can therefore best be brought about by the co-ordinated effort of service providers and policy makers. This means there is a role not only for Community Planning Partners, but also the Scottish Executive (sic) and private sector providers" (p. 5) [32].

Continuing to learn from leading international examples is essential, as the evidence-base in Scotland begins to move from anecdotal to systematic. One such example is Finland [49], where deliberate cross-sectoral integration over 20 years, through investment in time and partnership-building both vertically and horizontally, has led to significant improvement in sustainable service provision.

Thirdly, "investment" is used in order to differentiate from "spending", the former being a longer-term deployment of resources for outcomes that are recognized to take time to establish, build and maintain. "Spending" typically is shorter-term, linked with more rapid turnaround and expected payback on resource use. The rationale for investment is largely underpinned by three aspects; firstly, that what is needed to underpin infrastructure and service provision is increased capacity within the "system", across many sectors, people and communities. Secondly, that spending on short-term projects can and does lead to disincentivisation within communities and a dependency culture reliant on external project funding to pump-prime any and all developmental activity. Thirdly, that an investment timeframe allows for the possibility of tackling 'accessibility' rather than only 'access' components of the infrastructure and services landscape. These three elements are now briefly discussed.

Firstly, addressing infrastructure and service provision through multi-sectoral means involves multiple partners, perspectives and skills bases. It involves building functional partnerships, sometimes from the beginning. This cannot be achieved over-rapidly. The Scottish Government also recognizes the importance of involving communities (e.g., through Community Planning Partnerships) in partnering to address service access and accessibility challenges. The experience from Initiative at the Edge, reported in the evaluation, is significant here:

"Overall, the Initiative has had some success as a catalyst to achievement, but in its present form it has had limited success in addressing deep-seated underlying problems that demand a long planning horizon for their solutions. Community strengthening and development are desirable and provide a necessary underpinning for long-term sustainable regeneration" (p. ix, emphasis added) [32].

Dependence on local capacity raises issues of knowledge and skills required to ensure resilience of both the initiatives and the communities themselves. Systematic research into this within the informal and formal voluntary sector is gathering pace (Woolvin, pers. Comm. March 2010), such as through research into the importance of voluntary activity for the sustainability of village halls in Scotland [46]. Anecdotal evidence continues to suggest that although many communities do have the necessary composite of skills and knowledge within them, that is not universally the case, and there is need for 
greater understanding of what is required to support the contribution made by volunteers to rural community cohesion.

Research also shows [50-55] that there are a number of challenges to be addressed in ensuring inclusive participation by rural communities. Findings from these authors indicate that, under current processes of many rural development approaches, there is the potential for reinforcement of existing patterns of governance which favor an articulate and vocal minority. Secondly there is often the assumption that local perspectives are always "right" rather than also containing elements of parochialism which can lead to competition between rural communities for limited funds, for example. The teasing out of these aspects of bottom-up development is essential in ensuring the ongoing "fit" and thus increased sustainability of service and infrastructure provision in rural Scotland. The Remote Service Futures project [56] is one example of a development methodology seeking to enhance existing community capacity to engage in their health service futures, build functional partnerships in challenging (service-depletion) situations, and be as inclusive as possible. It is an "anticipatory service design" approach which seeks to engage communities before service restructuring is required, and could be a useful toolkit that could be applied within a longer-term context.

The second implication of short-term spending rather than long-term investment is illustrated amply through the evaluation of the Initiative at the Edge, the following two quotes being relevant:

"However, it is quite clear ... that momentum has been lost after the formal period of designation. The short life of the formal designation, followed by the loss of the IatE badge and the designation of further IatE areas is judged by some to have had a rather damaging effect on momentum" (p. vii) [32].

“... a fundamental difficulty is the placing of support staff on short-term contracts. The latter is an unhelpful feature because it creates instability and inefficiencies in the development process" (p. viii) [32].

These very specific comments reflect the wider recommendation of the OECD (2006) in their New Rural Paradigm that, for there to be sustainable rural development, there must be a shift from spending to investment, which reflects a shift from short to longer-term goals and mechanisms.

The third component which could be more adequately addressed through a longer time-frame is that of accessibility rather than simply access (although that is not to imply that access in itself is straightforward). In Scotland, much of the debate and focus in rural infrastructure and services continues to focus on provision of access [57] stated in coverage figures, rather than on "accessibility", that is, the capacity to engage with the provided services and infrastructure. For example, the Scottish Executive [35] review of services in rural Scotland focused on access issues of rural residents, highlighted as (p. 3):

- access to public transport including buses, trains and planes (routes, timetables, integration of different services) \& rising cost of private transport (fuel, tax, lack of petrol stations);

- access to health centres, GPs and emergency health services (limited opening hours, seniority of staff, withdrawal of other services such as mid-wife and health visitors, dental services); 
- access to other emergency services (withdrawal of the local 'bobby', longer travel times for the fire service etc.);

- access to refuse collection and recycling (frequency, high journey times) and poor quality ('poorly' implemented or badly communicated);

- access to post offices and retail shops (shops closing, limited choice, high travel times as a result, loss of community centre);

- quality of road maintenance and perceived short-termist view on maintenance ('patching up', heavy lorries);

- access to and quality of communication services (poor reception and service quality of telephone, mobiles, broadband, television);

- access and quality of utilities, water and energy (poor quality of product, poor service from staff, belief that rural locations were unimportant);

- access to, and quality of, housing.

However, there is a need to look beyond simple access, since, as Farrington states:

"Accessibility can be defined as 'the ability of people to reach and take part in activities and services normal for their society'. It is important for well-being since it enables social, commercial, educational, health, recreational and other interactions for the individual, family and social group. It is an essential means of achieving 'higher order goods' of, for example, education, social interaction, employment and income and health" [58].

In relation to rural Scotland, there is little evidence to suggest that accessibility as well as access is consistently and systematically prioritized within policy and projects. However, as has been discussed, there are a small number of examples of community engagement and capacity-building (such as Initiative at the Edge and Community Planning Partnerships) which acknowledge the importance of identifying ways to increase local "fit" of service delivery. This could be argued to have the potential to increase personal accessibility in such areas.

In conclusion, I therefore argue that, if strategic, cross-sectoral investment is not increasingly realised, rural Scotland will continue to have "hot spots" and "not spots" of infrastructure and service provision. This 'landscape' will persist, and is consequential given the basis of evidence presented which demonstrates the links between service provision and community sustainability (as defined above), and the corollary of "zones of depletion" where such infrastructure and services are weak. I suggest that the current approach remains "Darwinian", where the fittest and most articulate are able to access services and infrastructure, lever match-funds, and survive, potentially to the detriment of less able communities and regions. This appears to be the ongoing default position. Thus decisions need to be made, both in how we continue to research this field, and by those in policy analysis and implementation, as to whether this trajectory is acceptable, given the often implicit goals of rural (community) sustainability and the wider issue of social justice.

There is a need for ongoing interpretive analysis of policy, within and beyond the public sector. Such analyses, and the presentation of (dominant and lesser) narratives, can continue to delve more deeply into the "hidden frames" [59] of reference that underpin priorities and identification of 'solutions', and identify who the legitimate actors are in this challenging landscape. The range of actors is increasing at multiple levels. It is therefore essential that coexisting perspectives and 
storylines are explored and argued to identify potential meta-narratives [60]. Further, given the shift in language towards empowerment and engagement, research needs to bring deliberative analyses of policy and practice into the domain of rural services and infrastructure, in order to enhance mutual learning.

\section{Notes and References}

1. Fischer, F. Reframing public policy. In Discursive Politics and Deliberative Practices; Oxford University Press: Oxford, UK, 2003.

2. Services of General Interest; European Commission White Paper; European Commission: Brussels, Belgium, 2004.

3. Policy Brief: Reinventing Rural Policy; OECD: Paris, France, 2006.

4. Copus, A.K.; Johansson, M.; Johansson, M. One size fits all? Regional differentiation and rural development policy. Eurochoices 2007, 6, 13-21.

5. Grimes, S. Rural areas in the information society: Diminishing distance or increasing learning capacity? A report for the combat poverty agency. J. Rural Stud. 2000, 16, 13-21.

6. Skerratt, S. Evaluation of Scotland's Rural Community Gateway; Scottish Executive: Edinburgh, Scotland, 2006.

7. Farrington, F.; Edwards, P.; Skerratt, S. Technology in a Cold Climate: Interconnected Society. In Proceedings of the Royal Society of Arts Conference on Digital Society, London, UK, 2009.

8. Skerratt, S. Our digital futures: Policies for broadband connectivity in remote and rural communities of Ireland and Scotland. Scot. Aff. J. 2005, Autumn, No. 53.

9. Cairncross, F. The Death of Distance 2.0. How the Communications Revolution Will Change Our Lives; Harvard Business School Press: Boston, MA, USA, 2001.

10. Information \& Communication Technologies in Rural Society: Being Rural in a Digital Age; Rusten, G., Skerratt, S., Eds.; Routledge: Oxford, UK, 2008.

11. Servon, L.J. Bridging the Digital Divide: Technology, Community and Public Policy; Blackwell Publishing: Oxford, UK, 2002.

12. Social Justice-A Scotland Where Everyone Matters. Social Justice Annual Report; Scottish Executive: Edinburgh, Scotland, 2000.

13. Hall, C.; Skerratt, S. What is the future for Scotland's rural infrastructure and access to services? In Rural Scotland in Focus 2010; Skerratt, S., Hall, C., Lamprinopoulou, C., McCracken, D., Midgley, A., Price, M., Renwick, A., Revoredo, C., Thomson, S., Williams, F., Wreford, A., Eds.; SAC Rural Policy Centre: Edinburgh, Scotland, 2010, pp. 30-41.

14. Farrington, J.H. The new narrative of accessibility: Its potential contribution to discourses in (transport) geography. J. Transp. Geogr. 2007, 15, 319-330.

15. Farrington, J.H.; Farrington, C.J.T. Rural accessibility, social inclusion and social justice: Towards conceptualisation. J. Transp. Geogr. 2005, 13, 1-12.

16. Skerratt, S. The persistence of place: The importance of shared participation environments when deploying ICTs in rural areas. In Information \& Communication Technologies in Rural Society: Being Rural in a Digital Age; Rusten, G., Skerratt, S., Eds.; Routledge: Oxford, UK, 2008. 
17. Thomson, S. How is Scotland's rural population changing? In Rural Scotland in Focus 2010; Skerratt, S., Hall, C., Lamprinopoulou, C., McCracken, D., Midgley, A., Price, M., Renwick, A., Revoredo, C., Thomson, S., Williams, F., Wreford, A., Eds.; SAC Rural Policy Centre: Edinburgh, Scotland, 2010; pp. 9-17.

18. Fay, B. Social Theory and Political Practice; George Allen and Unwin: London, UK, 1975.

19. High-speed broadband is typically defined as next generation broadband (at least $2 \mathrm{MB} / \mathrm{second}$, but typically $8-16 \mathrm{MB} / \mathrm{second}$ ), as compared with standard broadband (up to $0.5 \mathrm{MB} / \mathrm{second}$ ).

20. Skerratt, S. The persistence of place: the importance of shared participation environments when deploying ICTs in rural areas, In Information \& Communication Technologies in rural society: Being rural in a digital age; Rusten, G., Skerratt, S., Eds.; Edited Research Monograph. Routledge: Oxford, England, 2008. (the same as Ref. 19)

21. Skerratt, S. How are Scotland's rural communities taking ownership of their own future. In Rural Scotland in Focus 2010; Skerratt, S., Hall, C., Lamprinopoulou, C., McCracken, D., Midgley, A., Price, M., Renwick, A., Revoredo, C.,Thomson, S., Williams, F., Wreford, A., Eds.; SAC Rural Policy Centre: Edinburgh, Scotland, 2010; pp. 42-51.

22. Farmer, J.; Hinds, K.; Richards, H.; Godden, D. Scottish rural and urban healthcare: A survey of access, satisfaction and expectations. J. Health Serv. Res. Policy 2005, 10, 212-219.

23. Scottish Neighbourhood Statistics Homepage. http://www.sns.gov.uk (accessed on 5 January 2010).

24. Rural Policy Review. Scotland, UK; OECD: Paris, France, 2008.

25. Public Transport-Availability of Bus Services: High Level Summary of Statistics Trend; Scottish Government: Edinburgh, Scotland, 2010; Available online: http://www.scotland.gov.uk/Topics/ Statistics/Browse/Transport-Travel/TrendBusServices (accessed on 5 January 2010).

26. Yanow, D. Conducting Interpretive Policy Analysis; Sage Publications: Thousand Oaks, CA, USA, 2000.

27. Infrastructure to 2030: Main Findings and Recommendations; OECD: Paris, France, 2006.

28. Infrastructure to 2030: Findings and Recommendations; OECD: Paris: France, 2007; Volume 2.

29. Stevens, B.; Schieb, P.A. Infrastructure: Mind the gap. OECD Observer, 2007, No. 263; Available online: http://www.oecdobserver.org/news/fullstory.php/aid/2411/Infrastructure:_Mind_the_gap. html (accessed on 1 February 2010).

30. Rural Scotland-People, Prosperity and Partnership: Rural Framework Themes, including "Effective Service Delivery" and "Networks and Communications". Available online: http://www. archive.official-documents.co.uk/document/scottish/r-scot/c1b1.htm (accessed on 10 October 2009).

31. Four of these pilot areas were in the Western Isles, namely Uig and Bernera, the Bays area of Harris, Eriskay and Lochboisdale. The other four were Westray and Papa Westray, North Sutherland, Ardnamurchan and Colonsay.

32. Review and Evaluation of Initiative at the Edge; Scottish Executive: Edinburgh, Scotland, 2007.

33. Closing the Opportunity Gap: CtOG Targets; Scottish Government: Edinburgh, Scotland, 2004; Available online: http://www.scotland.gov.uk/Topics/People/Social-Inclusion/17415/CtOGtargets/ctog-target-h (accessed on 20 July 2009). 
34. Community Planning Partnerships were introduced in 2003 as part of the Local Government in Scotland Act 2003. CPPs operate in all of Scotland's 32 Local Authorities, and are seen as integral to "a process which helps public agencies to work together with the community to plan and deliver better services which make a real difference to people's lives". See: http://www.scotland.gov.uk/Topics/Government/PublicServiceReform/community-planning (accessed on 1 November 2009).

35. Service Priority, Accessibility and Quality in Rural Scotland; Scottish Executive: Edinburgh, Scotland, 2006.

36. There is a third National Outcome which bears some relation to rural services and infrastructure provision, and is returned to later in the paper: "We have strong, resilient and supportive communities where people take responsibility for their own actions and how they affect others" (Outcome 11).

37. The extent to which a new localism is emerging is touched upon later in the paper.

38. Using the Randall Definition, there are 14 "rural" Local Authorities out of the total of 32. The Randall definition of rural Local Authorities is those containing less than 100 people per square kilometre.

39. Council News: Rural Proofing Policy Is a First for Scotland; Scottish Borders Council: St Boswell's, Scotland, 2007; Available online: http://www.scotborders.gov.uk/news/21401.html (accessed 1 April 2009).

40. Rural Proofing has been instigated in England, and was re-launched in May 2009. Evaluation (2007) by the Commission for Rural Communities shows it to be variable in its depth and delivery. Specifically: (i) programmes lack "rural awareness"; (ii) rural proofing is having little effect; (iii) it is dependent on individual champions rather than being systematic; (iv) it is not built in strategically.

41. Primrose, D.; Fawcett, J. Evaluation of the Scottish Executive's 'Broadband for Scotland' Intervention, 2007; Available online: http://www.scotland.gov.uk/Resource/Doc/212800/ 0056576.pdf (accessed on 1 August 2009).

42. See ISPreview's useful map showing composite broadband coverage for Scotland, as a result of various initiatives. Available online: http://www.ispreview.co.uk/story/2009/05/19/overviewscotlands-25m-gbp-universal-broadband-coverage.html (accessed on 5 January 2010).

43. MacAskill, N. In Focus: The role of the voluntary sector in Scotland's rural development. In Rural Scotland in Focus 2010; Skerratt, S., Hall, C., Lamprinopoulou, C., McCracken, D., Midgley, A., Price, M., Renwick, A., Revoredo, C., Thomson, S., Williams, F., Wreford, A., Eds.; SAC Rural Policy Centre: Edinburgh, Scotland, 2010; p. 47.

44. People and Communities: Services and Lifestyle: Economy and Enterprise; Scottish Government: Edinburgh, Scotland, 2009; Available online: http://www.scotland.gov.uk/Publications/2009/09/ 24095407/0 (accessed on 5 January 2010).

45. Challenges to the Rural Voluntary Sector, SCVO, Glasgow, Scotland, 2003; Available online: http://www.scvo.org/scvo/Information/ViewInformation.aspx ?al=t\&page=\&all=\&from=DSR\&Inf o=176\&TCI (accessed on 10 October 2009). 
46. Skerratt, S.; MacLeod, M.; Hall, C.; Duncan, R.; Strachan, M.; Harris, J.; Moseley, M.; Farmer, J. Community Facilities in Rural Scotland: A Study of Their Use, Provision and Condition; Scottish Government Social Research: Edinburgh, Scotland, 2008.

47. COSLA; SOLACE; IS. Interim Report from Local Government on the First Phase Single Outcome Agreements in 2008-2009; COSLA: Edinburgh, Scotland, 2009.

48. Scotland Performs, Scottish Government, Edinburgh, Scotland, 2009; Available online: http://www.scotland.gov.uk/About/scotPerforms/indicators (accessed on 1 July 2009).

49. Rural Policy Review Finland; OECD: Paris, France, 2008.

50. Shortall, S. Social or economic goals, civic inclusion or exclusion: An analysis of rural development theory and practice. Sociol. Ruralis. 2004, 44, 110-124.

51. Shortall, S. Are rural development programmes socially inclusive? Social inclusion, civic engagement, participation and social capital. Exploring the differences. J. Rural Stud. 2008, 24, 450-457.

52. Shucksmith, M. Endogenous development, social capital and social inclusion: Perspectives from LEADER in the UK. Sociol. Ruralis. 2000, 40, 208-219.

53. Participation: The New Tyranny? Cooke, B., Kothari, U., Eds.; Zed Books: London, UK, 2001.

54. Hickey, S.; Mohan, G. Participation: From Tyranny to Transformation? Exploring New Approaches to Participation in Development; Zed Books: London, UK, 2004.

55. Skerratt, S.; Slee, B. Rural development after 2013. In Proceedings of the Joint Agricultural Economics Society and SFER Conference on the CAP beyond 2013, Edinburgh, Scotland, 29 March 2010.

56. Nimegeer, A.; Farmer, J.; West, C.; Whiston, S.; Heaney, D. Remote Service Futures: Health Care Service Design with Communities-Final Report; UHI Millennium Institute Centre for Rural Health: Inverness, Scotland, 2010.

57. Where "access" is defined as "travel time, physical accessibility, opening hours, services being brought in to a region, level of personal contact, response time, regularity of service, reliability and capacity" (Scottish Executive, 2006, p. 7).

58. Farrington, J. In Focus: Accessibility in Rural Areas. In Rural Scotland in Focus 2010; Skerratt, S., Hall, C., Lamprinopoulou, C., McCracken, D., Midgley, A., Price, M., Renwick, A., Revoredo, C., Thomson, S., Williams, F., Wreford, A., Eds.; SAC Rural Policy Centre: Edinburgh, Scotland, 2010; p. 35.

59. Hoffman, M. Defining and evaluating success: Facilitative problem-solving workshops in an interconnected context. Paradig.: Kent J. Int. Relat. 1995, 9, 150-167.

60. Roe, E. Narrative Policy Analysis: Theory and Practice; Duke University Press: Durham, NC, USA, 1994.

(C) 2010 by the authors; licensee MDPI, Basel, Switzerland. This article is an Open Access article distributed under the terms and conditions of the Creative Commons Attribution license (http://creativecommons.org/licenses/by/3.0/). 